\title{
Retained bile duct stones in a patient with Billroth II gastrectomy: extracorporeal shock wave lithotripsy and papillary dilatation via $\mathrm{T}$ tube
}

\author{
R Nitsche, U R Fölsch
}

\begin{abstract}
A postoperative $\mathbf{T}$ tube cholangiogram after cholecystectomy in a 62 year old patient showed two retained calculi of $14 \mathrm{~mm}$ diameter each. Endoscopic sphincterotomy was not possible because of previous Billroth II gastrectomy. The stones were disintegrated by electromagnetically generated extracorporeal shock waves. The $\mathbf{T}$ tube was replaced by a balloon catheter and the papilla of Vater was dilatated allowing passage of stone fragments. We conclude that retained bile duct stones can be removed without sphincterotomy or percutaneous extraction by extracorporeal shock wave lithotripsy and papillary dilatation. This method should be considered especially in patients with Billroth II gastrectomy.
\end{abstract}

Retained common bile duct stones after cholecystectomy continue to be a problem in 2 to

Department of Internal
Medicine, Division of
Gastroenterology and
Endocrinology, Georg-
August-Universität
Göttingen, D 3400
Göttingen, West
Germany
R Nitsche
U R Fölsch
Correspondence to:
Dr Rolf Nitsche, I
Department of Internal
Medecine,
Christien-Albrechts-
Universität Kiel Schittenhelm
72, D2300 Kiel, Germany.
Accepted for publication
26 March 1990

Department of Internal Medicine, Division of Gastroenterology and Endocrinology, Georg Göttingen, D 3400 Göttingen, West Germany

Ritsche

Correspondence to: Dr Rolf Nitsche, I Department of Internal Universität Kiel Schittenhelm 26 March 1990
Figure 1: Postoperative cholangiogram via T tube showing two retained bile duct calculi.
$5 \%$ of the patients who have undergone surgery, despite the common use of operative cholangiography. ${ }^{1}$ There are two possible ways to extract retained stones: (a) via the $T$ tube channel using a Burhenne basket and (b) via endoscopic retrograde cholangiopancreatography and sphincterotomy. In patients with Billroth II gastrectomy, however, endoscopic sphincterotomy carries a higher risk and fails in at least $35 \%$. $^{2}$

We report the successful combination of extracorporeal shock wave lithotripsy (ESWL) and papillary dilatation via the $T$ tube channel in a patient with retained bile duct stones and Billroth II gastrectomy.

\section{Case report}

A 62 year old man was wounded 45 years ago by a shot through the stomach for which he underwent surgery. Seven years later a Billroth II gastrectomy was performed for duodenal ulcers. Subsequently, biliary colic with jaundice led to cholecystectomy with common duct exploration in March 1989. A postoperative T tube cholangiogram (Fig 1) showed two retained calculi (14 $\mathrm{mm}$ each) in the common bile duct. Endoscopic sphincterotomy was impossible and attempts to dissolve the stones with EDTA and monooctanoin failed. The patient was therefore referred to our hospital four weeks after cholecystectomy.

The density of the stones, measured by computed tomography, was $47 \mathrm{HU}$ suggesting that they consisted of cholesterol. ${ }^{3}$ It was decided to disintegrate them by ESWL using the Lithostar lithotripter (Siemens, Erlangen, West Germany). The bile ducts were opacified via a $T$ tube and the stones were located by fluoroscopy. Three ESWL sessions were undertaken and 2500 shock waves were applied to each stone at an energy level of $18 \cdot 1 \mathrm{kv}$. Because the second treatment session had to be interrupted due to pain despite intravenous opiate analgesia, the third treatment was performed with ketamin anaesthesia. Altogether 5000 shock waves were applied.

The stones disintegrated and most of the fragments disappeared spontaneously while rinsing the bile duct with standard electrolyte solution via the $\mathrm{T}$ tube. Some small fragments remained, however (Fig 2). Using a J tipped 
Figure 2: Stone fragment after three sessions of extracorporeal shock wave lithotripsy treatment (altogether 5000 shock waves) using a Lithostar lithtripter (Siemens, Erlangen, FRG).

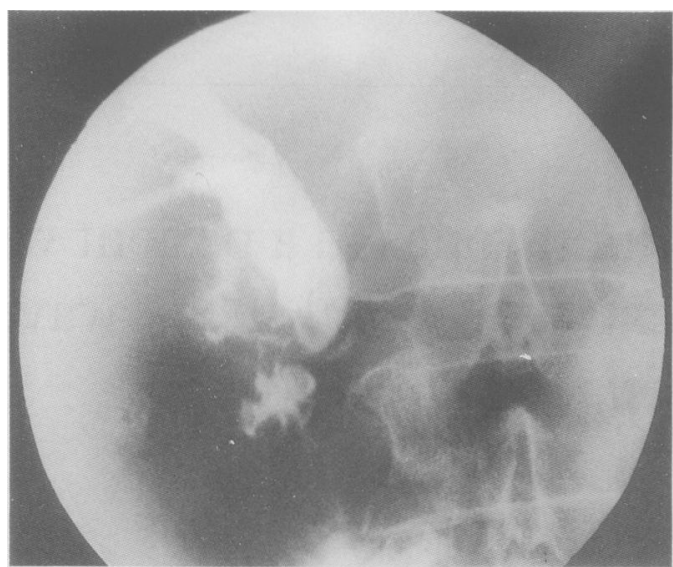

guide wire, the $\mathrm{T}$ tube was replaced by a balloon catheter (Vygon, Aachen, FRG), which was passed through the papilla of Vater into the duodenum (Fig 3). The position of the balloon in the papillary segment was confirmed by fluoroscopic control. The catheter consists of a double lumen tube with a total length of $195 \mathrm{~cm}$ and outer diameter of $1.5 \mathrm{~mm}$. The banana shaped balloon has a length of $4 \mathrm{~cm}$ and a diameter of 1.5 $\mathrm{cm}$ after full insuflation with air or water. The free end of the catheter distal to the balloon amounts to $4 \mathrm{~cm}$. The sphincter was dilated by inflating the balloon to its full diameter by $10 \mathrm{ml}$ air for 20-30 seconds. This was repeated four times. After this procedure the contrast medium quickly passed through the papillary segment and the small fragments disappeared into the duodenum by rinsing the bile duct with $0.9 \%$ saline. The final $x$ ray examination confirmed that the bile duct was free of stones and the catheter was removed (Fig 4).

\section{Discussion}

After cholecystectomy, the usual treatment of bile duct stones is endoscopic sphincterotomy. In patients with Billroth II gastrectomy, however, endoscopic treatment fails in at least $35 \%$. $^{2}$ Shortly after cholecystectomy, the T tube offers another possible method of treating retained stones. Burhenne reported on the percutaneous extraction of retained biliary tract stones through the $T$ tube sinus tract in 661 patients. ${ }^{+}$For this procedure, a time interval of five to seven weeks after cholecystectomy is necessary for the formation of the sinus tract wall. Moreover, only stones up to $6-8 \mathrm{~mm}$ in diameter can be

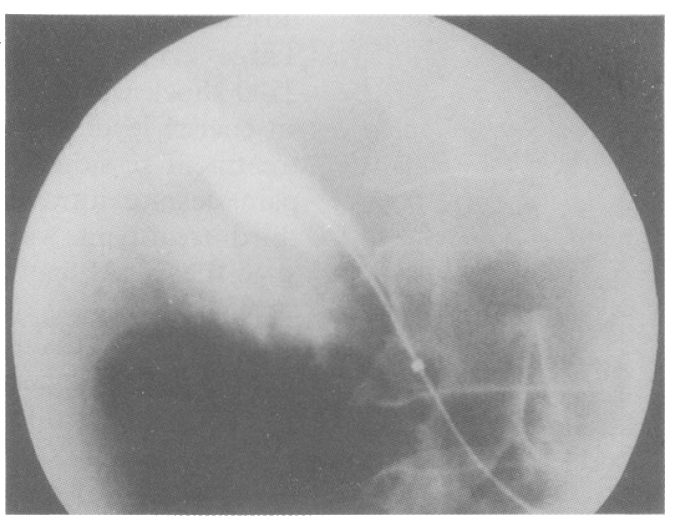

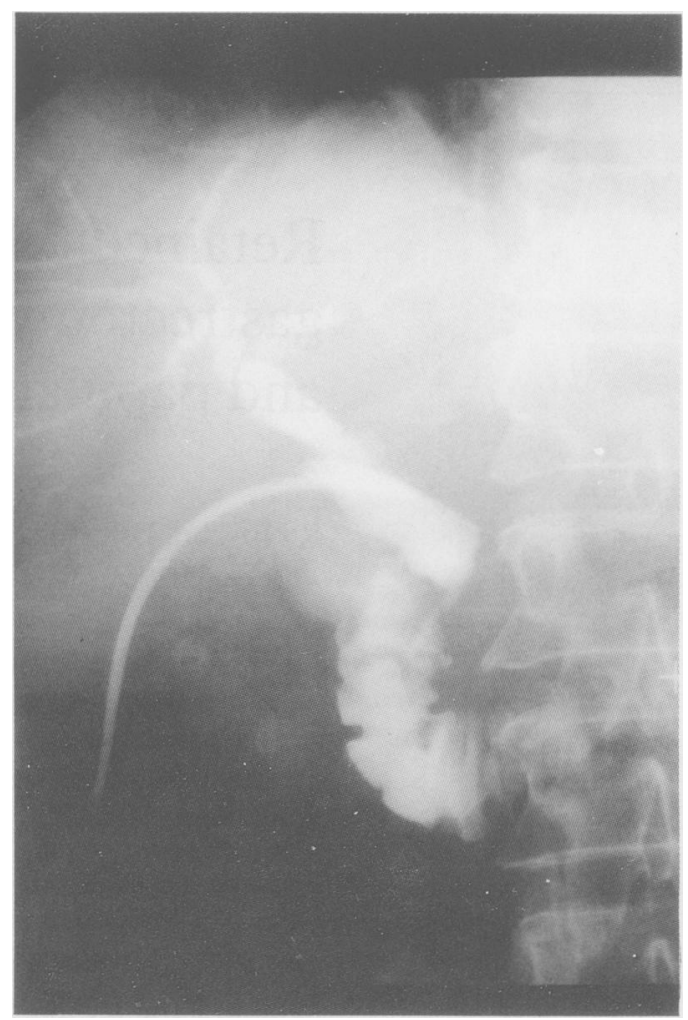

Figure 4: Cholangiogram after extracorporeal shock wave lithotripsy and balloon dilatation: the bile duct is free of stones or fragments.

extracted. Larger stones require fragmentation, which can be achieved either mechanically with a basket $^{5}$ or by local application of shock waves. ${ }^{6}$

Meanwhile, reports using ESWL on bile duct stones with electrohydraulically, ${ }^{7}$ electromagnetically, ${ }^{8}$ and piezoelectrically ${ }^{9}$ generated shock waves have been published. Johlin treated large retained stones with ESWL and extracted the remaining fragments either through the $T$ tube channel or via endoscopic sphincterotomy. ${ }^{10}$ One of the major problems after ESWL is the removal of the fragments, especially in patients with Billroth II gastrectomy. The combination of ESWL and percutaneous extraction of the fragments was also reported by Becker. "Darzi ${ }^{12}$ dissolved the fragments after ESWL with methyltertbutylether.

Papillary dilatation ${ }^{13-15}$ carries a lower risk than sphincterotomy and percutaneous extraction. In this patient all fragments of the retained bile duct stones passed through the papilla of Vater after ESWL and papillary dilatation, supported by rinsing the bile duct with electrolyte solution. Anaesthesia with Ketamin for ESWL treatment is unusual. In none of the 24 other patients with bile duct stones treated in our unit was Ketamin application necessary for ESWL (about 30 sessions). Compared with alternative treatments, ESWL in combination with papillary dilatation carries a minimal risk only. This method should be considered, especially in patients with Billroth II gastrectomy.

1 Beal JM. Gallbladder and biliary tract. In: Hardy JD, ed. Hardy's textbook of surgery. Philadelphia: JB Lippincott, 1983: 657-78.

2 Sáfrány L, Neuhaus B, Portocarrero G, et al. Endoscopic sphincterotomy in patients with Billroth II gastrectomy. Endoscopy 1980; 12: 16-22. tip of the catheter is positioned deeply in the duodenum. The inflated both radiopaque points. 
3 Staritz M, Wosiewitz U, Rambow A, et al. Computertomographie zur Bestimmung der Zusammensetzung von graphie zur Bestimmung der Zusammensetzung von Gallenblasen- und Gallengangssteinen: Vergleich

4 Burhenne HJ. Percutaneous extraction of retained biliary tract tones: 661 patients. $A \mathcal{F R} 1980 ; 134: 888-98$.

5 Bethge N, Nintze RE. Endoskopische lithotripsie von gallengangssteinen. Z Gastroenterol 1987; 25: 119-23.

6 Hwang MH, Lee HH, Lin J, et al. Transcholecystic endoscopic choledocholithotripsy: successful management of retained common bile duct stone. Endoscopy 1987; 19: 24-7.

7 Sauerbruch T, Stern M. Fragmentation of bile duct stones by extracorporeal shock waves. Gastroenterology 1989; 96: $146-52$.

8 Staritz M, Rambow A, Floth A, et al. Extrakorporale stoßwellenlithotripsie von gallensteinen. Schweiz Rundsch Med Prax 1988; 77: 6-11.

9 Weber J, Esser M, Riemann JF. Successful Piezoelectric lithotripsy of a common bile duct stone. Endoscopy 1989; 21 145-7.
10 Johlin FC, Loening SA, Maher JW, et al. Electrohydraulic shock wave lithotripsy (ESWL) fragmentation of retained shock wave lithotripsy (ESWL) fragmentation

11 Becker CD, Fache JS, Gibney RG, et al. Treatment of retained cystic duct stones using extracorporeal shockwave lithotripsy. $A 7 R$ 1987; 148: 1121-2.

12 Darzi A, Monson JR, Keane FB, et al. Combined extracorporeal shock wave lithotripsy in the dissolution of retained common bile duct stone [Abstract]. Gastroenterology 1988; 94: A87.

13 Groen JN, Lock MT, Lameris JS, et al. Removal of common bile duct stones by the combination of percutaneous balloon dilatation and extracorporeal shock wave lithotripsy. Gastroenterology 1989; 97: 202-6.

14 Staritz M, Ewe K, Meyer zum Büschenfelde KH. Endoscopic papillary dilatation, a possible alternative to endoscopic papillotomy. Lancet 1982; i: 1306-7.

15 Ullrich D, Fölsch UR, Weigel M, et al. Choledochal cyst type I: successful endoscopic balloon dilatation of the distal common bile duct and sphincter of Oddi: a case report. Z Gastroenterol 1986; 24: 195-9. 